\title{
Histórias de vida e estigma de trabalhadores com
transtornos mentais acompanhados em ambulatório especializado
}

\author{
Alessandra Renata Geremias ${ }^{1}$ \\ Universidade Estadual de Campinas (Campinas, SP, Brasil) \\ Paulo César Zambroni-de-Souza ${ }^{2}$ \\ Universidade Federal da Paraíba (João Pessoa, PB, Brasil) \\ Sérgio Roberto de Lucca ${ }^{3}$ \\ Universidade Estadual de Campinas (Campinas, SP, Brasil)
}

Este estudo de abordagem qualitativa teve como objetivo conhecer, analisar e compreender como a retirada de direitos sociais e trabalhistas interferiu na vida e no trabalho de pessoas com transtornos mentais graves. Foram realizadas entrevistas em profundidade com 11 participantes, oito homens e três mulheres, atendidos(as) em um ambulatório de Psiquiatria de um hospital universitário, com uso de roteiro semiestruturado, e realizou-se análise de conteúdo. Os resultados indicam que a trajetória de trabalho dos(as) participantes iniciou-se na infância e adolescência, de modo que todos exerciam atividades de trabalho quando receberam o diagnóstico. A necessidade de afastamento, as dificuldades relacionadas ao retorno e a retirada de parte das pessoas do mundo do trabalho foram evidenciadas. Em face disso, foram discutidos os prejuízos sociais e trabalhistas após o diagnóstico de transtorno mental relatados pelos participantes. O processo de estigmatização apareceu no ambiente de trabalho, familiar e comunitário e contribuiu para o declínio da carreira e remuneração ou para a saída dos trabalhadores de suas atividades.

Palavras-chave: Transtornos mentais, Trabalho, Estigma.

Life stories and social stigma of workers with mental disorders followed up in a specialize outpatient clinic in Campinas, Brazil

This qualitative approach study aimed to know, analyze, and understand how the withdrawal of social and labor rights interfered in the life and work of people with severe mental disorders. In-depth interviews with eleven participants, eight men and three women who were assisted at a psychiatric outpatient clinic of a university hospital, were performed. Semi-structured script interviews were conducted and content analysis was performed. The results indicate that the work trajectory of the participants began in childhood and adolescence, so that all performed work activities when they received diagnosis. The study highlighted the need for medical leave, the difficulties related to the return, and the withdrawal from work environment of part of the people interviewed. In view of this, the social and labor losses after the diagnosis of mental disorder reported by the participants were discussed. The stigmatization process manifested in their work, family and community environments and contributed to the decline in career and remuneration or to the withdrawal from their activities.

Keywords: Mental disorders, Work, Stigma. 


\section{Introdução}

presente artigo tem como objetivo conhecer, analisar e compreender como retirada de direitos sociais e trabalhistas para o corpo social como um todo interfere na vida e no trabalho de pessoas com transtornos mentais graves (TMG). Por compreender que o campo da saúde do trabalhador tem o saber acadêmico como uma de suas bases (Lacaz, 2007), este texto toma o conceito de Estigma (Corrigan et al., 2011; Goffman, 1693/1981; Kyff, 2007; Link \& Phelan, 2001) como referência principal, colocando-o em diálogo com a Psicologia Social do Trabalho, Saúde Coletiva, Sociologia do Trabalho e Serviço Social.

Diante do crescente desrespeito do chamado mercado de trabalho para com os seres humanos (Stiglitz, 2002) e da crescente precarização à qual trabalhadores(as) estão submetidos(as) nas últimas décadas, poderia se pensar: qual seria o motivo de se interessar pelo trabalho em sua relação com pessoas com transtornos mentais graves? Defendemos que, exatamente por estarmos em uma época de perda de direitos, tornam-se urgentes soluções para tal questão, em especial para aqueles(as) que vivenciam as maiores dificuldades, como as pessoas com TMG.

\section{Trabalho, vida e saúde}

O trabalho é uma atividade social que ocupa centralidade na vida das pessoas no campo econômico, cultural, psíquico e social. Para além de uma atividade individual, o trabalho produz uma relação das pessoas entre si e com os outros e do seu potencial criador e humanizador (Praun, 2016). Além disso, contribui para construção de sentido, identidade e autoestima e busca de equilíbrio psíquico.

Segundo Sato et al. (2017), para pensar as relações intersubjetivas no trabalho é necessário situá-las no contexto social do qual são parte, chamando a atenção para as particularidades que as relações e condições de trabalho assumem em diferentes sociedades, e que podem favorecer ou restringir suas condições de vida.

A precarização do mundo do trabalho contemporâneo teve impactos negativos para a vida da maior parte dos trabalhadores e trabalhadoras, com perda de direitos e redução da autonomia pessoal e profissional (Antunes, 2018; Seligmann-Silva et al., 2010). A partir das últimas décadas do século XX, o neoliberalismo passou a se colocar como o único modo possível de gerir a produção e a vida, apregoando que "There Is No Alternative", conforme as palavras de Herbert Spencer (1851, p. 31), retomadas por Margaret Thatcher, que ficaram conhecidas pela sigla TINA. Tal modelo estimula a competição entre as pessoas e mina a cooperação, gera ansiedade e leva ao adoecimento, através de avaliações individuais de desempenho, avaliações quantitativas; incentiva a competição entre os trabalhadores, que ficam solitários e amedrontados.

Sabe-se que os anos de 1970 foram época de grandes crises econômicas mundiais que tiveram como uma de suas principais saídas o neoliberalismo (Stiglitz, 2002), que estabeleceu um modo de funcionar organizacional que estimula que cada um procure sempre produzir mais a qualquer custo (inclusive subjetivo), incita a competição e desestimula a cooperação, tendendo a destruir os coletivos, deixando cada um à sua própria sorte, fragilizado (Dejours, 2012, 2013), quadro que afeta a dinâmica das relações familiares e sociais, além da própria saúde. Ao lado disso, busca-se cada vez mais os trabalhadores free lancers ao invés de assalariados (Dejours, 2009). Tais formas de gestão, "fundadas na glorificação da autonomia e da excelência" (Leclerc, 2005), tendem a deixar as pessoas solitárias e a destruir os coletivos.

Nos processos de sofrimento e desenvolvimento dos transtornos mentais, é imprescindível considerar que eles estão relacionados com as condições psicossociais individuais e coletivas, podendo ser agravados e potencializados pelas condições socioeconômicas, tais como o desemprego, a violência, a pobreza e as desigualdades sociais e étnicas (Jongsma et al., 2018; Organização Pan-Americana de Saúde, 2018). 


\section{Estigma}

Verifica-se uma relação entre transtornos mentais e o prejuízo da condição e capacidade de trabalho de pessoas com este tipo de diagnóstico (Vechi et al., 2017; Vieira et al., 2016). Entre 2012 e 2016, cerca de 668 mil trabalhadores(as) com carteira assinada com transtornos mentais se afastaram do trabalho por mais de 15 dias com benefícios previdenciários de auxílio-doença ou aposentadorias por invalidez (Previdência Social, 2017). Esses dados são ainda subestimados porque não incluem os(as) trabalhadores(as) informais que representam $46 \%$ da nossa força de trabalho e, quando adoecidos(as), permanecem invisíveis nas estatísticas oficiais (Organização Internacional do Trabalho, 2018).

Além disso, historicamente, observam-se dificuldades de as sociedades lidarem com as pessoas rotuladas como "portadoras de transtornos mentais" (Corrigan et. al, 2011; Goffman, 1963/1981), e com isso são estabelecidas barreiras psicossociais que prejudicam a trajetória de vida e de trabalho dessas pessoas. Nesse cenário, o estigma social relacionado ao transtorno mental desponta como uma das principais barreiras.

O conceito de estigma remete a um modo de identificação de pessoas por meio de características valoradas negativamente e que expõem a pessoa ou grupo estigmatizado ao desvalor do seu atributo. Sua origem na Grécia o identificava como uma marca corporal realizada para destacar pessoas e grupos do demais por apresentarem alguma peculiaridade e para a distinção de classe social (Goffman, 1963/1981; Liddell \& Scott, 1996). No uso latino, o "estigma" visava a marcar também pessoas escravizadas fugitivas e sinalizava "desgraça" (Lewis \& Short, 1969). No correr dos séculos, o conteúdo do termo passou a versar sobre "marca" de vergonha e descrédito, como também ponto mórbido no corpo (Kyff, 2007).

Diante disso, o estigma do transtorno mental está entre os fatores que contribuem para a deterioração das condições de vida e saúde das pessoas com transtornos mentais. $\mathrm{O}$ modo estigmatizante, ao lidar com as pessoas com transtornos mentais, traz prejuízos para suas vidas e seus cuidados de saúde.

A saúde mental ainda é uma área muito negligenciada, visto que, em países de baixa e média renda, a prevalência das pessoas com transtornos mentais que não recebem tratamento é de $76 \%$ a $85 \%$, enquanto em países de alta renda essa taxa varia entre $35 \%$ e $50 \%$ das pessoas com transtornos mentais desassistidas (Organização Pan-Americana de Saúde, 2018).

No Brasil o movimento da Reforma Psiquiátrica substitutiva do modelo asilar ampliou a assistência e o cuidado em saúde mental e trouxe incontáveis contribuições (Desviat, 2015). Entretanto, verifica-se que as dificuldades nas condições de vida e de trabalho das pessoas com transtornos mentais, associadas ao estigma e desvalorização social, ainda persistem em nosso país (Carvalho \& Lins, 2015; Pereira \& Joazeiro, 2015; Salles \& Barros, 2013).

Vale destacar que a pesquisa apresentada aqui foi realizada antes da pandemia de Covid19, que agravou o desemprego e a situação de vida e trabalho da maioria da população, comprometendo ainda mais a assistência para as pessoas com doenças crônicas, em especial aquelas com diagnóstico de transtornos mentais (Lucca, 2020).

Tudo isso dificulta a possibilidade de acesso, permanência e retorno ao mundo do trabalho de mulheres e homens com transtornos mentais.

\section{Método}

\section{Tipo de estudo}

Trata-se de um estudo de abordagem qualitativa, na modalidade de história de vida, com o uso do recurso da entrevista em profundidade para a compreensão das vivências e percepções dos(as) participantes. Buscou-se valorizar o significado atribuído pelos(as) participantes da pesquisa ao fato pesquisado e a intensidade dos fenômenos, valores, crenças, opiniões, modos de 
relações, símbolos, comportamentos, representações e práticas daquilo que se pretende conhecer (Minayo, 2017).

\section{Participantes}

Participaram da pesquisa pessoas com diagnósticos de transtornos mentais considerados graves como Esquizofrenia, Transtorno Afetivo Bipolar e Depressão com sintomas psicóticos, que, embora apresentem sintomatologias diferentes, são consideradas graves pelas repercussões desses sofrimentos, mesmo sabendo que eles apresentam prognósticos distintos, sendo o de Esquizofrenia o menos favorável dentre eles, como afirmam Sadock et al. (2017, p. 370):

Estudos sobre o curso e o prognóstico dos transtornos do humor de modo geral concluíram que essa condição tende a apresentar cursos longos e que os pacientes têm propensão à recidiva. Embora os transtornos do humor sejam considerados benignos, em comparação com a esquizofrenia, representam uma profunda carga sobre os indivíduos afetados.

Seguindo Basaglia, os autores concordam que o diagnóstico estabelecido pela Psiquiatria corre sempre o risco de assumir o "o valor de um rótulo que codifica uma passividade dada como irreversível” (1968/1985, p. 108), como ocorreu desde o início daquele campo de saber (Foucault, 1961/ 1987). O presente artigo não pretende debater a relação de poder presente nesse âmbito e toma como ponto de partida o fato de que as pessoas que participaram da pesquisa que o originou sofrem muitas vezes dificuldades imensas na relação consigo mesmas, com os familiares e com o corpo social, o que dificulta frequentemente sua inserção e manutenção nos mundos do trabalho. A estabilidade, ou a falta dela, do quadro clínico interfere diretamente na capacidade de uma pessoa trabalhar ou não, mas não se pode esquecer que essas pessoas são ativas e podem laborar (Zambroni-de-Souza, 2006a), não devendo ser reforçado o estigma segundo o qual são incapazes para a vida e o trabalho.

Foram adotados como critérios de inclusão dos participantes: idade igual ou superior a 18 anos, tratamento psiquiátrico por diagnóstico de transtorno mental e história de exercício de atividades de trabalho em algum momento da vida, independente de vínculo empregatício, e ter compreendido e assinado o Termo de Consentimento Livre e Esclarecido (TCLE).

O universo de participantes foi composto por conveniência, conforme os critérios de inclusão. No total, 14 pessoas foram convidadas para participar do estudo, sendo nove homens e cinco mulheres, entretanto, três se recusaram, ficando 11 delas.

\section{Lócus e procedimento}

A coleta de dados foi realizada no período de dezembro de 2018 a março de 2019, em um hospital público universitário de referência, localizado no município de Campinas, interior do Estado de São Paulo. Foram realizadas 12 visitas ao ambulatório pela primeira autora e, após as consultas realizadas pelos residentes de psiquiatria, pessoas que atendiam ao critério de inclusão foram convidadas a participar da pesquisa. Todas as entrevistas foram realizadas em um consultório no próprio serviço, pela pesquisadora, sem a participação de terceiros.

\section{Instrumento}

Realizou-se uma única entrevista semiestruturada com cada participante, com um roteiro previamente construído com questões abertas, com margem para alterações e acréscimos durante o contato com o(a) participante. As entrevistas foram gravadas e sua duração média foi de 30 a 40 minutos.

O roteiro construído pelos pesquisadores continha dados sociodemográficos (idade, raça/cor [autodeclarada], sexo, orientação sexual, escolaridade, estado civil, configuração familiar, situação de moradia, profissão e situação no mercado de trabalho), questões 
disparadoras acerca da história de trabalho (idade de início da atividade laboral, tipo de trabalho, carga horária, relacionamento com colegas e gerência, desempenho das atividades de trabalho, afastamento e retorno ao trabalho) e história de saúde mental (início do acompanhamento, primeiro episódio, internações, uso de medicações psicotrópicas e cuidado recebido).

\section{Análises dos materiais}

O conteúdo das narrativas, após a transcrição, foi analisado pela metodologia de análise de conteúdo formulada por Bardin (1977/2011), e foram adotados nomes fictícios para uso dos discursos. Após a análise flutuante das falas, que possibilitou as primeiras aproximações com o conteúdo e um conhecimento prévio do texto, foi realizada a análise do conteúdo. Realizou-se uma categorização semântica, seguindo as etapas de "inventário" com o isolamento dos elementos e a "classificação", sendo esta analógica e progressiva, com a divisão dos elementos e organização das mensagens. A etapa final desse processo foi o estabelecimento e titulação das categorias analíticas. As categorias analíticas, portanto, emergiram das falas dos(as) participantes, não tendo sido estabelecidas previamente.

\section{Conformidade ética}

O projeto desta pesquisa atende aos requisitos de ética em pesquisa, aprovado pelo Comitê de Ética em Pesquisa (CEP) da instituição de ensino com o número 9511618.80000.5404. Todas as participações ocorreram após o conhecimento e aceite do Termo de Consentimento Livre e Esclarecido.

\section{Resultados e discussão} 1.

As características e dados sociodemográficos dos participantes estão descritos no quadro

Quadro 1: Dados sociodemográficos dos participantes da pesquisa atendidos em ambulatório de Psiquiatria no município de Campinas, 2019

\begin{tabular}{|c|c|c|c|c|c|c|c|c|c|}
\hline Participante & Sexo & Idade & Escolaridade & $\begin{array}{c}\text { Mora com } \\
\text { a família }\end{array}$ & $\begin{array}{c}\text { Trabalha } \\
\text { atualmente }\end{array}$ & Última ocupação & $\begin{array}{c}\begin{array}{c}\text { Já foi afastado do } \\
\text { trabalho por Saúde } \\
\text { Mental? }\end{array} \\
\end{array}$ & $\begin{array}{c}\text { Idade do } \\
\text { diagnóstico }\end{array}$ & $\begin{array}{c}\text { Diagnóstico } \\
\text { (transtorno } \\
\text { mental) }\end{array}$ \\
\hline André & M & 34 & EF incompleto & Sim & Não & Açougueiro & Sim & 18 & $\begin{array}{c}\text { TAB e Transtorno } \\
\text { relacionado ao uso } \\
\text { de substâncias }\end{array}$ \\
\hline João & $\mathrm{M}$ & 19 & EM incompleto & Sim & Não & Serralheiro & Sim & 17 & \begin{tabular}{|c|}
$\mathrm{TAB}$ \\
\end{tabular} \\
\hline Carlos & M & 53 & EF incompleto & Não & Não & Serviços gerais & Sim & 42 & $\begin{array}{c}\text { Transtorno } \\
\text { depressivo com } \\
\text { sintomas psicóticos }\end{array}$ \\
\hline Ana & $\mathrm{F}$ & 47 & $\mathrm{EF}$ & Sim & Sim & Diarista & Sim & 46 & TAB \\
\hline Rosa & $\mathrm{F}$ & 66 & $\mathrm{EF}$ & Sim & Sim & Costureira & Sim & 40 & \begin{tabular}{|c|} 
Transtorno \\
depressivo com \\
sintomas psicóticos
\end{tabular} \\
\hline Valéria & $\mathrm{F}$ & 59 & $\begin{array}{c}\text { ES- Ciências } \\
\text { Sociais } \\
\end{array}$ & Sim & Sim & $\begin{array}{c}\text { Agente de saúde da } \\
\text { atenção básica }\end{array}$ & Sim & 33 & $\mathrm{TAB}$ \\
\hline Adão & M & 50 & EM & Sim & Sim & \begin{tabular}{|c|} 
Motorista de \\
aplicativo e porteiro
\end{tabular} & Sim & 46 & Esquizofrenia \\
\hline Antônio & M & 69 & $\begin{array}{l}\text { ES- Ciências } \\
\text { Contábeis }\end{array}$ & Não & Não & Contador & Não & 50 & $\mathrm{TAB}$ \\
\hline Joaquim & M & 50 & $\begin{array}{l}\text { ES-Análise de } \\
\text { Sistemas }\end{array}$ & Sim & Não & $\begin{array}{c}\text { Gerente de } \\
\text { multinacional }\end{array}$ & Sim & 47 & $\begin{array}{c}\text { Transtorno } \\
\text { Depressivo com } \\
\text { sintomas psicóticos }\end{array}$ \\
\hline Jorge & M & 47 & $\begin{array}{l}\text { ES- Tecnologia } \\
\text { da informação }\end{array}$ & Sim & Sim & $\begin{array}{c}\text { Analista na área de } \\
\text { informática }\end{array}$ & Sim & 33 & Esquizofrenia \\
\hline Joel & M & 40 & $\begin{array}{l}\text { ES- Tecnologia } \\
\text { da informação }\end{array}$ & Sim & Não & Analista de T.I. & Sim & 30 & TAB \\
\hline
\end{tabular}

Fonte: Compilação dos autores.

Legenda: $\mathrm{M}=$ masculino; $\mathrm{F}=$ feminino; $\mathrm{EF}=$ Ensino Fundamental completo; EF incompleto= Ensino Fundamental incompleto; $\mathrm{EM}=$ Ensino Médio completo; EM incompleto= Ensino Médio incompleto; ES= Ensino Superior completo; T.I.= Tecnologia de Informação; $\mathrm{TAB}=$ Transtorno Afetivo Bipolar. 
A população deste estudo foi composta por 11 participantes, oito homens e três mulheres. Com relação à raça/etnia autodeclarada, oito pessoas declararam-se brancas, constituindo a maioria desse grupo, uma negra, uma morena e uma parda. A respeito da escolaridade dos(as) participantes, cinco concluíram o ensino superior, duas o ensino médio e quatro o ensino fundamental.

As categorias e subcategorias de análise estão indicadas no quadro 2. Foram destacados fragmentos representativos dos conteúdos expressos pelos participantes.

Quadro 2: Categorias de análise presente no discurso dos participantes da pesquisa realizada em ambulatório de Psiquiatria em Campinas no ano de 2019

\begin{tabular}{|c|c|c|}
\hline Categorias de análise & $\begin{array}{c}\text { Subcategorias de } \\
\text { análise }\end{array}$ & Exemplos dos conteúdos manifestos pelos participantes \\
\hline \multirow{3}{*}{ Trabalho } & $\begin{array}{c}\text { Primeira experiência } \\
\text { de trabalho }\end{array}$ & $\begin{array}{l}\text { "Foi aos } 13 \text { anos... espetava carne." (André) } \\
\text { "Comecei cedo, acho que eu tinha uns } 14 \text { anos de idade... eu era babá." } \\
\text { (Ana) } \\
\text { "Eu nasci na roça e com } 7 \text { anos eu já ia pra roça ajudar minha família } \\
\text { nas tarefas." (Adão) }\end{array}$ \\
\hline & Sentido e Significado & $\begin{array}{l}\text { "Você está fazendo sua vida, sua rotina, coisas que te deixam } \\
\text { feliz... Todo emprego ensina alguma coisa pra pessoa..." (João) } \\
\text { "Eu trabalhava de feriado, de domingo, de sábado, achando que o } \\
\text { serviço ia me tirar aquilo, eu não entendia que tava com depressão." } \\
\text { (Ana) }\end{array}$ \\
\hline & Mulher e trabalho & $\begin{array}{l}\text { "há } 26 \text { anos tive a minha primeira depressão, foi um dos tempos que } \\
\text { fiquei sozinha com as crianças e o que eu fazia, não tinha estudo, eu } \\
\text { ia trabalhar de doméstica, dar banho em doente, fazer tudo o que eu } \\
\text { sabia fazer." (Rosa) } \\
\text { "Muito trabalho, marido, casa, juntou tudo ... eu tava com } \\
\text { dificuldades." (Ana) }\end{array}$ \\
\hline $\begin{array}{l}\text { Estigma relacionado ao } \\
\text { trabalho e convívio social }\end{array}$ & $\begin{array}{c}\text { Estigma social, estigma } \\
\text { internalizado e } \\
\text { estrutural }\end{array}$ & $\begin{array}{l}\text { "Ninguém fala abertamente, mas as pessoas, familiares, têm isso como } \\
\text { algo que te diminui ..." (Jorge) } \\
\text { "Esquizofrenia ... essa palavra é pesada pra mim, mas tenho que aceitar, } \\
\text { melhor que louco." (Adão) } \\
\text { "Eu não espalho pra evitar qualquer tipo de problema, porque as } \\
\text { pessoas começam a te enxergar diferente." (Jorge) }\end{array}$ \\
\hline $\begin{array}{l}\text { Repercussões da doença e o } \\
\text { difícil processo de retomada } \\
\text { das atividades de trabalho }\end{array}$ & $\begin{array}{l}\text { Início dos sintomas } \\
\text { Afastamentos } \\
\text { Retorno ao trabalho }\end{array}$ & $\begin{array}{l}\text { "Como veio um laudo falando da minha doença eu achei que tinha sido } \\
\text { mandado embora por isso." (Carlos) } \\
\text { "Eu acho que isso é o grande paradigma para todos que passam por uma } \\
\text { internação psiquiátrica, é como se você tivesse que aprender a fazer } \\
\text { tudo de novo." (Joel) }\end{array}$ \\
\hline
\end{tabular}

Fonte: Compilação dos autores.

De modo não intencional, a maioria dos participantes do estudo é do sexo masculino, cujo recorte se assemelha a estudos realizados anteriormente com pessoas com transtornos mentais considerados graves (Cardoso et al., 2006; Costa, 2008; Oliveira et al., 2018). Com relação aos homens em acompanhamento na saúde mental, Clezar et al. (2018) evidenciaram a maior prevalência da esquizofrenia no sexo masculino (Cardoso et al., 2006), enquanto outros estudos observaram os prejuízos na qualidade de vida no caso do transtorno afetivo bipolar (Costa, 2008).

Ainda sobre a predominância dos participantes do sexo masculino, salienta-se que, culturalmente, a expectativa relacionada ao gênero masculino está fortemente relacionada à virilidade e produtividade. Neste contexto, o homem tido como louco sofre pela impossibilidade de corresponder à expectativa social e com a perda do lugar privilegiado na socialização masculina que é parte de seu aspecto identitário, do seu modo de ser nessa sociedade e por meio do qual constitui sua subjetividade, apresentando importantes rompimentos na socialização e consideráveis prejuízos para a qualidade de vida (Zanello et al., 2015).

\section{Vivências de trabalho e os significados atribuídos a ele}

A maioria dos participantes iniciou as atividades de trabalho doméstico e rural ainda na infância ou adolescência, entre oito e quatorze anos de idade, com a finalidade de contribuir com o sustento do grupo familiar. 
Ao abordar o trabalho de crianças e adolescentes, estudos apontaram as perdas de momentos de vida, com alijamento do direito e acesso à educação, menor tempo para estudo e qualificação profissional (Thomé et al., 2010), tendo como consequência piores níveis de saúde (Dall'Agnol et al., 2015; Kassouf et al., 2001; Nishijima et al., 2015), perdas subjetivas pelo comprometimento de momentos importantes para o desenvolvimento, redução da autoestima e autorrealização (Costa et al., 2015) e menor remuneração na fase adulta (Monte, 2008; Souza \& Pontili, 2007).

O trabalho precoce faz com que crianças e adolescentes assumam atribuições e responsabilidades incompatíveis com seu estágio de desenvolvimento e pertencentes à vida adulta, sem estarem preparados física e psiquicamente para assumir tais compromissos. Adaptamse de modo estereotipado, incorporando comportamentos, valores, papéis e tarefas que comprometem a identidade do "ser criança" e consequentemente o futuro do seu "ser adulto" (Silva, 2002).

$\mathrm{Na}$ direção das pesquisas realizadas, a maior parte dos homens e mulheres participantes do nosso estudo iniciou suas trajetórias profissionais sob o encargo do trabalho precoce como a perda de momentos importantes para desenvolvimento e socialização, assumindo responsabilidade familiar precoce, com a alfabetização prejudicada e/ou interrompida.

Rosa verbalizou: "Não tinha estudo, eu ia trabalhar de doméstica, dar banho em doente, fazer tudo o que eu sabia fazer ... Eu achava pouco porque na verdade queria fazer veterinária, medicina ou agronomia". No seu relato começou a trabalhar aos oito anos, responsabilizando-se pelos cuidados domésticos, enquanto os pais realizavam seus trabalhos fora da residência e, com nove anos, ela passou a trabalhar com a mãe na colheita de algodão. O gosto pela atividade rural que a levou a desejar a formação superior foi impedido pelo exercício precoce como trabalhadora rural, que a afastou da escola e da continuidade dos seus estudos durante a infância e adolescência. Tal situação estabelece um limite social que, embora seja conhecido desde o surgimento da Psicopatologia do Trabalho (Le Guillant, 2006), ainda hoje permanece produzindo estigmas nas pessoas, gerando ressentimentos socialmente produzidos, com os quais um sujeito não consegue lidar sem a mudança de sua condição de vida e trabalho, como mostra o relato dessa participante.

Assim como Rosa, outros participantes vivenciaram na vida adulta os prejuízos em aspectos objetivos e subjetivos, e aqueles(as) que iniciaram suas atividades de trabalho mais precocemente possuíam menos anos de escolaridade, condição esta que os tornou mais vulneráveis e "reféns" de profissões ou ocupações com condições de maior exploração de trabalho e menor remuneração. É possível sinalizar que os participantes que adentraram no mundo do trabalho ainda crianças têm em suas trajetórias de vida o sofrimento e prejuízos advindos do trabalho precoce, em um cenário triste e corriqueiro no Brasil (Alberto et al., 2020), naturalizando o estigma e banalizando a injustiça social (Dejours, 2007).

Apesar do Estatuto da Criança e do Adolescente (Lei no 8.069/1990), o trabalho precoce, por muitos anos "naturalizado", fez (e ainda faz) parte do cotidiano de milhares de brasileiros(as) e atinge principalmente as populações mais pobres em busca de sobrevivência, encobrindo os danos físicos, mentais, sociais e econômicos consequentes desse processo.

É com esses rebatimentos que o sentido e significado do trabalho foram construídos para os participantes. Nessa direção, Valéria se expressou: "Eu me sinto útil, me sinto bem porque eu tenho uma área de atuação". João também atribuiu um sentido positivo ao trabalho na sua vida: "Eu gosto muito de trabalhar porque você ocupa a mente ... está ganhando seu dinheiro, você está fazendo sua vida, sua rotina".

A centralidade do trabalho na vida econômica, psíquica e social das pessoas se materializa como exercício de cidadania, aquisição de renda, autoafirmação e como espaço de relacionamento social e construção de um lugar, não se limitando a uma forma de satisfação de necessidades básicas de subsistência, representando também uma fonte de construção de identidade, autoestima, possibilidade de desenvolvimento de competências e um modo de sentirse parte da sociedade (Navarro \& Padilha, 2007). 
As falas dos participantes apontaram também uma conotação assumida socialmente do "trabalhar" como sinônimo de utilidade e de ocupação, que os distancia de pensamentos "danosos". Essa concepção, vinculada a uma valoração moral, nos remete a um tipo de ideário que impõe padrões nos quais uma pessoa, para ser valorizada e se manter em um "bom caminho", precisa estar inserida no mundo do trabalho, sem considerar as condições reais em que o trabalho se realiza no modo de produção em que vivemos.

Por outro lado, mesmo acreditando que laborar teria sido importante para afastá-los da suposta nocividade que se apresentaria a eles caso tivessem se mantido ociosos, os participantes também observaram efeitos negativos do trabalho, destacando o excesso de tempo dedicado à atividade e a ausência de momentos de vida fora do trabalho: "Eu tava só trabalhando, tentando sustentar uma coisa, não só financeiramente, isso vai te deixando desgostoso, era ruim" (João).

A precarização do mercado de trabalho tem expressões como o aumento progressivo da exploração, a subtração do tempo de vida fora do trabalho e os impactos no significado do trabalho, contribuindo para danos à saúde física e mental dos trabalhadores (Antunes, 2018). Essa organização contemporânea do trabalho favorece o sofrimento e desgaste de modo coletivo com uma multiplicidade de manifestações para a saúde, uma vez que as pessoas têm modos particulares de vida e subjetividade (Benach et al., 2014).

As participantes mulheres também apontaram importantes elementos acerca da divisão sexual do trabalho que são representativos da realidade brasileira. Rosa, Valéria e Ana realizam atividades de trabalho relacionadas ao cuidado. Valéria trabalha como agente de saúde; Rosa, que atualmente trabalha como costureira, já trabalhou como cuidadora; e Ana trabalha como diarista. As profissões relacionadas ao cuidado, que empregam uma parte significativa das mulheres, carecem de valorização social e econômica, além de reforçar o papel social atribuído ao feminino (Dejours, 2004; Hirata, 2016).

Além disso, essas mulheres ainda estão sobrecarregadas pelas responsabilidades domésticas e de cuidado de seus familiares, fato expresso em suas falas: "Eu tava muito estressada, bem cansada, cuidando de casa, de criança e trabalhando fora, tava muito puxado pra mim..." (Ana); "Deixei tudo para cuidar da minha mãe, eu perdi o direito de ir e vir" (Rosa).

O trabalho doméstico não reconhecido e não remunerado é um aspecto de gênero não valorizado nesta sociedade, se sobrepondo ao limite das vidas femininas dentro e fora do mundo do trabalho, cuja sobrecarga contribui para a ocorrência de transtornos mentais comuns (Pinho \& Araújo, 2012).

\section{Estigma relacionado ao trabalho e convívio social}

O estigma foi expresso pelos participantes em diferentes momentos dos relatos e representou uma categoria-chave de análise de toda a temática da pesquisa.

O estigma, como uma conotação negativa, guarda conexões com estereótipo, o preconceito e a discriminação. As expressões do estigma podem ser identificadas como social, internalizado e institucional (Corrigan et al., 2011). O estigma social ocorre quando os estereótipos negativos relacionados a um grupo são endossados por parte significativa da sociedade. O estigma internalizado corresponde ao processo de assimilação e internalização dos estereótipos e preconceitos sobre si mesmo e a grupos com características semelhantes. O estigma institucional manifesta-se por meio de regras, políticas, procedimentos que restringem a participação de pessoas estigmatizadas, reduzindo suas possibilidades de vida.

A fala de João, a seguir, é reveladora de como as circunstâncias e processos estigmatizantes afetaram diferentes esferas da sua vida e impactaram suas chances e projetos (Link \& Phelan, 2001), tanto em aspectos objetivos, como trabalho, renda, formação acadêmica, participação social, quanto subjetivos, como autoimagem, autoestima, confiança, entre tantos outros prejuízos.

Eu não tenho o ensino médio completo. Parei quando fui internado pela primeira vez e não quis mais voltar pra escola porque tinha toda uma questão envolvida que eu tinha vergonha. Eu 
pensava que não ia ser mais igual às outras pessoas ... Meu tio tinha problema mental, esquizofrenia. Ele era na dele, não teve mulher, não teve filhos, ficou na casa da mãe dele e os meus outros parentes falavam que eu era tão parecido ...Por um tempo, achei que ia mesmo ficar como ele, não conseguir fazer nada (João).

O estereótipo negativo assimilado pelo participante identifica a pessoa com transtorno mental como incapaz de conduzir sua vida como as outras pessoas. Ademais, a internação psiquiátrica tornou-se motivo de "vergonha" para João, limitando seus projetos de vida, como o de escolarização.

Nesse processo de estigmatização de pessoas com transtornos mentais, emergiram nas entrevistas três componentes: medo, autoritarismo e benevolência (Corrigan et al., 2011).

O medo associado ao transtorno mental é justificado socialmente pelo discurso de periculosidade e imprevisibilidade, a despeito das tentativas de desconstrução desse pensamento e estudos que demonstram que as pessoas com transtornos mentais sofrem mais violências do que as praticam (Barretto \& Figueiredo, 2019; Nunes \& Torrenté, 2009). A fala de João exemplifica esse aspecto: "Eu tava com outra realidade, eu tava com medo, susto ... mas não estava agressivo, eu nunca fiquei agressivo".

O autoritarismo se legitima no entendimento de que as pessoas com diagnóstico de transtornos mentais são incapazes de decidir sobre suas vidas e tratamento, devendo o poder de decisão ser delegado ao outro. André e João referiram ter vivido situações em que "Quando eu acordei, minha mãe falou 'vamos ali comigo', aí eu fui e ela me internou numa clínica” (André); "Todo mundo vem tirar com a minha cara 'você tá surtando, vou te internar', eu fiquei por um bom tempo não gostando disso" (João).

A benevolência aparece por meio da percepção de que a pessoa com transtorno mental demanda um excessivo cuidado, com estabelecimento muitas vezes de uma relação paternalista e indesejada. Valéria relatou uma preocupação nessa direção: "Eu não quero ser a coitadinha, também não quero que as pessoas digam 'ela é bipolar', então...”.

$\mathrm{Na}$ análise dos discursos dos participantes da pesquisa, aspectos relacionados ao estigma foram evidenciados no âmbito do trabalho: "Esse problema que me deu, eu falo sozinho até hoje, a gente acaba sendo até um pouco antissocial" (Adão); "O garoto é louquinho, vamos dar uma mixaria pra ele, vamos explorar', eu vi coisas que eu não gostei e preferi não ficar mais naquele ambiente" (João).

Os elementos destacados nas falas de Adão e João evidenciaram o estigma social e seus componentes e que se configuram como importantes obstáculos para uma vida autônoma e possibilidades de trabalho (Rocha, Hara, \& Paprocki, 2015). Nessa direção, Adão também relatou: "Se você fala um negócio desse [diagnóstico] é discriminado, ninguém sabe, somente minha família mesmo, não falo isso para ninguém. Capaz de perder o emprego". Valéria também compartilhou uma preocupação nessa direção:

No Centro de Saúde tem um grupo de saúde mental e eu vejo como eles se posicionam perante as pessoas, como eu mesma vou dizer que tenho se eu vejo que as pessoas que têm e vão lá com o diagnóstico não são entendidas, não são compreendidas.

Como elucidado por Goffman (1981, p. 52), o ocultamento do diagnóstico por parte da pessoa estigmatizada é uma forma de ter uma "aceitação involuntária" por pessoas que têm preconceito contra o tipo de pessoa que ele(a) poderia revelar ser. É afastar do conhecimento geral a informação que o(a) tornaria desacreditado(a).

O medo de não ser aceito, de sofrer preconceito e discriminação por parte do empregador e colegas de trabalho e ser demitido implicou a omissão do diagnóstico e limitou a forma de ação, de relacionamento no ambiente de trabalho e, para alguns participantes, impossibilitou a sua permanência na atividade. Durante as entrevistas, participantes relataram o estabelecimento de relações mais distanciadas dos colegas, o não posicionamento frente a algumas demandas ou situações conflituosas como forma de manter em "segredo" seu diagnóstico, pois, uma vez conhecida a situação de sofrimento mental, seus comportamentos poderiam ser identificados 
como sintomas dos transtornos mentais, colocar em xeque a credibilidade até então existente no local de trabalho e colocá-los(as) em uma situação desvantajosa perante os outros colegas de trabalho.

Nas palavras de Dejours (2011, p. 15): "face à dominação, à injustiça, ao assédio, à ameaça de demissão, cada qual se encontra doravante sozinho" e contribuem para o sofrimento mental.

\section{Repercussões do transtorno mental e o difícil processo de retomada da atividade de trabalho}

O modo como os sintomas de sofrimento mental afetou as relações de trabalho foi recontado pelos participantes, como discorrem Adão, José e Ana: "Eu não conseguia desenvolver mais minhas atividades ... eu cheguei num ponto que eu tava louco dentro da empresa" (Adão); "Eu tive pânico, uma angústia muito forte ... nesse período não dá pra trabalhar" (José); "Como eu tava doente não podia limpar janela, tinha serviço limitado" (Ana).

As narrativas dos participantes da pesquisa sugerem que lidar com as "formalizações, prescrições e determinações" durante os primeiros episódios foram impraticáveis. Quando existe a "desestabilização" no âmbito da saúde mental, as demandas do mercado de trabalho podem acrescer mais sofrimento do que representar possibilidade de saúde (Zambroni-de-Souza, 2006b).

A necessidade de afastamento da atividade de trabalho no contexto de "crises" foi narrada por alguns participantes. O período de afastamento do trabalho foi em torno de um ano para a maioria deles, como relembra Valéria, "sim eu recebi um ano ... quando é doença mental não tem como saber se a pessoa tem mesmo ou não".

Os transtornos mentais e comportamentais são a terceira causa de afastamento do trabalho por período superior a 15 dias e de concessão de aposentadoria por invalidez (Previdência Social, 2017). Já os trabalhadores informais, quando se afastam do trabalho durante as crises, permanecem sem renda ou benefício, com agravamento da situação de vulnerabilidade. Muitos dos(as) participantes da pesquisa vivenciaram período de adoecimento sem garantia de renda, impossibilidade de sustento e com risco direto de perda da atividade de trabalho.

A ausência de estratégias eficazes de retorno ao trabalho pode prolongar o afastamento ou comprometer a volta à atividade. A indisposição da empresa em acolher o trabalhador afastado por transtorno mental, a insegurança e o receio em voltar ao trabalho são elementos que dificultam esse processo.

Fiquei uns seis meses afastado do trabalho... eu queria ficar um pouco mais de tempo, tava com medo de voltar, mas daí disseram "você vai voltar." Depois, quando eu queria voltar, disseram "não, você não vai voltar", era sempre o contrário (Jorge).

Ainda com relação ao tempo de afastamento do trabalho, características sociodemográficas (idade, sexo, escolaridade), fatores psicossociais no trabalho, história de afastamento prévio, condições de saúde e as particularidades do transtorno mental podem ter influência. $O$ tempo médio de afastamento do trabalho dos participantes desta pesquisa foi de seis meses a um ano e o tempo prolongado de afastamento da atividade de trabalho também é considerado um aspecto prejudicial para a retomada da atividade laboral, como já referido em estudos anteriores (Blank et al., 2008; D’Amato \& Zijlstra, 2010).

O processo de retomada da atividade de trabalho ocorreu após a estabilização dos sintomas e foi recontado pelos participantes, conforme as narrativas: "Formei em 1989, trabalhei com pesquisa e, depois, dei aula um ano. A medicação deixa a gente com falta de concentração ... por isso é que eu trabalho agora como agente de saúde" (Valéria); "Na indústria, era superperigoso, máquina, equipamento ... de porteiro, eu não faço nada que ponha em risco, de motorista tem o risco, mas eu não tô tendo problema" (Adão); "Eu voltei, demora um tempo pra você pegar o jeito ... Depois eu mudei de setor" (Jorge).

O transtorno mental impossibilitou a permanência nas antigas tarefas no caso da pesquisadora Valéria, do metalúrgico Adão e do analista de informática Jorge, entretanto, eles 
não estão incapacitados. A reinserção em atividades compatíveis e sem prejuízos deveria ser uma prerrogativa ética e social. Nesse sentido, as instituições e as empresas deveriam criar condições para a reinserção saudável desses profissionais que sofrem com o estigma associado às pessoas com transtornos mentais.

A severidade do sofrimento e das dificuldades das pessoas com transtornos mentais para desempenho de atividades de trabalho antes realizadas não indica uma dificuldade ou incapacidade completa (Zambroni-de-Souza, 2006a). No entanto, persiste a incompreensão nesse sentido, sustentada por fatores dentre os quais se destaca a conformação do mercado de trabalho no contexto neoliberal e seu caráter altamente excludente. Em vista disso, a desvalorização favorecida pelo estigma adiciona dificuldades aos(às) trabalhadores(as) com transtornos mentais ao reconhecê-los(as) como "anormais", "instáveis", "incapazes", "potencialmente violentos", "possivelmente faltosos e com necessidade de licenças médicas".

Foram ainda destacadas pelos participantes as perdas de remuneração devido à alteração do tipo de trabalho realizado após o adoecimento: "O dinheiro não dá ... O que ganho é mais pra pagar o aluguel e comprar mistura e, ainda assim, se acabar o gás, eu deixo de comprar mistura" (Carlos); "o salário de porteiro é muito pouco pra manter uma família igual eu tenho. No passado, eu tinha um bom salário, eu fiz uma casa grande, pra manter a casa o salário de porteiro não dá" (Adão).

Todos(as) os(as) participantes retornaram ao trabalho, porém, quando foram entrevistados, observou-se os efeitos do estigma social. Valéria e Jorge trabalhavam com vínculo formal, entretanto em atividades diversas daquelas realizadas anteriormente. Ana e Rosa exerciam atividades na informalidade, sem a garantia dos direitos trabalhistas e expostas à precarização dessas atividades. Adão, que também teve mudança de área de atuação após o diagnóstico, reunia as condições de trabalhador terceirizado em sua atividade de porteiro e trabalhador sem vínculo trabalhista na sua atividade de motorista de aplicativo, convivendo com os prejuízos dessas duas formas de inserção no mercado de trabalho. André, João, Joel e Joaquim encontravam-se com ônus objetivo e subjetivo do desemprego, enquanto Antônio e Carlos estavam aposentados, sendo este último na modalidade "aposentadoria por invalidez".

\section{Considerações finais}

A história de vida e trabalho dos(as) participantes reúne semelhanças quanto ao início precoce nas atividades de trabalho, a vivência de sofrimento mental quando as exerciam, experiências de afastamentos e retornos difíceis ao mundo do trabalho. Em suas trajetórias, após o diagnóstico de transtorno mental, foram intensificadas as dificuldades para a participação social, escolarização, carreira, remuneração, assim como houve comprometimentos da autoestima, confiança e identidade. Cada participante viveu a seu modo perdas de direitos sociais e trabalhistas, e este estudo pretendeu evidenciar, para além das experiências individuais, a dimensão coletiva e social dessa retirada de direitos do corpo social para pessoas com transtornos mentais graves.

O processo de estigmatização foi apontado no ambiente de trabalho, familiar e comunitário e considerado uma chave de análise das perdas vividas por contribuir significativamente com as dificuldades vividas pelos(as) participantes para a participação social, em que se inclui o trabalho.

No cenário atual, o mercado de trabalho é altamente excludente, competitivo e estigmatizador no tocante ao adoecimento dos trabalhadores, em especial aqueles que se afastam por transtornos mentais. Além disso, o trabalho informal como modo de inserção possível e o desemprego também evidenciam como a precarização do mundo do trabalho impacta a maior parte da população e sobrepõe dificuldades às pessoas com transtornos mentais.

Com este artigo, pretendeu-se ter contribuído para reforçar a centralidade do trabalho na vida de todos os humanos e para lançar luz às dificuldades vivenciadas por essas pessoas com TMG por ocasião de sua tentativa de se colocar no mercado de trabalho. Intenta-se também 
colaborar com o desenvolvimento de estratégias inclusivas e que possam oferecer possibilidade de autonomia a essas pessoas pelo acesso ao trabalho e participação social.

\section{Referências}

Alberto, M. F. P., Pessoa, M. C. B., Malaquias, T. A. P., \& Costa, S. S. (2020). Trabalho infantil e ato infracional: análise histórico-cultural do desenvolvimento infantojuvenil. Revista Da Spagesp, 21(1), 127-142. http://pepsic.bvsalud.org/scielo.php?script=sci_arttext\&pid=S1677-29702020000100010

Antunes, R. (2018). Adeus ao trabalho? Ensaio sobre as metamorfoses e a centralidade do mundo do trabalho (16 ${ }^{\mathbf{a}}$ ed.). Cortez.

Bardin, L. (2011). Análise de conteúdo. Almedina. (Trabalho original publicado em 1977).

Barretto, R. S. \& Figueiredo, A. E. B. (2019). Estigma e violência na percepção dos profissionais de saúde mental de uma unidade psiquiátrica em hospital geral. Cadernos de saúde coletiva, 27(2), 124-130. https://www.scielo.br/scielo.php?script=sci_arttext\&pid=S1414-462X2019000200124

Basaglia, F. (1985). As instituições da violência. In A instituição negada: relato de um hospital psiquiátrico (pp. 99-133). Graal. (Trabalho original publicado em 1968).

Benach, J., Vives, A., Amable, M., Vanroelen, C., Tarafa, G., \& Muntaner, C. (2014). Precarious Employment: understanding an emerging social determinant of health. Annual Review of Public Health, 35(1), 229-253. https://doi.org/10.1146/annurev-publhealth-032013-182500

Blank, L., Peters, J., Pickvance, S., Wilford, J., \& MacDonald, E. (2008). A systematic review of the factors which predict return to work for people suffering episodes of poor mental health. Journal of Occupational Rehabilitation, 18(1), 27 34.

Cardoso, C. S., Caiaffa, W. T., Bandeira, M., Siqueira, A. L., Abreu, M. N. S., \& Fonseca, J. O. P. (2006). Qualidade de vida e dimensão ocupacional na esquizofrenia: uma comparação por sexo. Cadernos de Saúde Pública, 22 (6), 1303-1314. https://doi.org/10.1590/S0102-311X2006000600019

Carvalho, J. D. \& Lins, C. B. A. (2015). Um Hospital Geral e suas concepções da loucura. Revista Latinoamericana de Psicopatologia Fundamental, 18(2), 383-393.

Clezar, E. M., Bianchi, G. N., \& Garcia, L. S. B. (2018). Análise da readmissão hospitalar do paciente com diagnóstico de esquizofrenia em um hospital psiquiátrico de referência no sul catarinense. Arquivos Catarinenses de Medicina, 47 (3), 133-145.

Corrigan, P. W., Roe, D., \& Tsang, H. W. H. (2011). Challenging the stigma of mental illness: lessons for therapists and advocates (1를 ed.). Wiley-Blackwell.

Costa, A. M. N. (2008). Transtorno afetivo bipolar: carga da doença e custos relacionados. Archives of Clinical Psychiatry, 35(3), 104-110. https://doi.org/10.1590/S0101-60832008000300003

Costa, E. M., Souza, R. L. V., \& Kirst, P. B. A. G. (2015). Trabalho infantil: um estudo sobre os danos biopsicossociais percebidos pelos pesquisadores. Aletheia, 46, 131-141.

Dall'Agnol, M. M., Fassa, A. G., Facchini, L. A., \& Benvegnú, L. A. (2015). Associação do trabalho infantil com transtornos de comportamento do tipo introversão e extroversão: um estudo transversal no sul do Brasil. Revista Brasileira de Saúde Ocupacional, 40(132), 206-218. https://doi.org/10.1590/0303-7657000106414

D'Amato, A. \& Zijlstra, F. (2010). Toward a climate for work resumption: the nonmedical determinants of return to work. Journal of Occupational and Environmental Medicine, 52(1), 67-80.

Dejours, C. (2004). As relações domésticas: entre amor e dominação. In S. Lancman, L. I. Sznelman, \& I. Laerte (Orgs.), Christophe Dejours: da psicopatologia à psicodinâmica do trabalho (pp. 317-336). Editora Fiocruz.

Dejours, C. (2007). A banalização da injustiça social. Fundação Getúlio Vargas.

Dejours, C. (2009). Entre o desespero e a esperança: como re-encantar o trabalho. Cult. 139(12), 49-53.

Dejours, C. (2011). Psicopatología del trabajo - Psicodinámica del trabajo. Laboreal, 7(1), 13-16. 
Dejours, C. (2012). La panne: repenser le travail et changer la vie. Bayard.

Dejours, C. (2013). A sublimação, entre sofrimento e prazer no trabalho. Revista Portuguesa de Psicanálise. Lisboa, 33 (2), 9. 28.

Desviat, M. (2015). A reforma psiquiátrica (2ª ed.). Editora Fiocruz.

Foucault, M. (1987). História da loucura na idade clássica. Perspectiva. (Trabalho original publicado em 1961).

Goffman, E. (1981). Estigma: notas sobre a manipulação da identidade deteriorada (4⿳⺈冂䒑 ed.). LTC. (Trabalho original publicado em 1963).

Hirata, H. (2016). O Trabalho de cuidado. Revista Internacional de Direitos Humanos, 13(24), 53-64.

Jongsma, H. E., Gayer-Anderson, C., Lasalvia, A., Quattrone, D., Mulè, A., Szöke, A., Selten, J.-P., Turner, C. et al. (2018). Treated incidence of psychotic disorders in the multinational EU-GEI Study. JAMA Psychiatry, 75(1), 36-46. https://doi.org/10.1001/jamapsychiatry.2017.3554

Kassouf, A. L., McKee, M. \& Mossialos, E. (2001). Early entrance to the job market and its effect on adult health: evidence from Brazil. Health Policy and Planning, 16(1), 21-28. https://doi.org/10.1093/heapol/16.1.21

Kyff, R. (2007). Stigmas, Or Stigmata? Courant.Com. https://www.courant.com/news/connecticut/hc-xpm-2007-11-20. 0711190402-story.html

Lacaz, F. A. C. (2007). O campo Saúde do Trabalhador: resgatando conhecimentos e práticas sobre as relações trabalhosaúde. Cadernos de Saúde Pública, 23(4), 757-766.

Leclerc, C. (2005). Intervir conta o assédio moral: cuidar e reprimir não basta. Laboreal, 1(1), 65-78.

Lei 8.069, de 13 de julho de 1990. (1990). Dispõe sobre o Estatuto da Criança e do Adolescente. Presidência da República.

Le Guillant, L. (2006). Incidências psicopatológicas da condição de empregada doméstica. In M. E. A. Lima (Org.), Escritos de Louis Le Guillant: da ergoterapia à psicopatologia do trabalho (pp. 242-286). Vozes.

Liddell, H. G. \& Scott, R. (1996). A Greek-English Lexicon: with a revised supplement (9a ed.). Clarendon Press.

Link, B. G., \& Phelan, J. C. (2001). Conceptualizing Stigma. Annual Review of Sociology, 27(1), 363-385. https://doi.org/10.1146/annurev.soc.27.1.363

Lucca, S. R. (2020). Coronavírus: o trabalho sob fogo cruzado. Cadernos de Saúde Pública, 36(9). https://www.scielosp.org/article/csp/2020.v36n9/e00237120/

Minayo, M. C. S. (2017). Amostragem e saturação em pesquisa qualitativa: consensos e controvérsias. Revista Pesquisa Qualitativa, 5(7), 01-12.

Monte, P. A. (2008). Exploração do Trabalho Infantil no Brasil: consequências e reflexões. Revista EconomiA, 9(3), 625-650.

Navarro, V. L. \& Padilha, V. (2007). Dilemas do trabalho no capitalismo contemporâneo. Psicologia ESSociedade, 19(nspe.), 14-20. https://doi.org/10.1590/S0102-71822007000400004

Nishijima, M., Souza, A. P. F., \& Sarti, F. M. (2015). Trends in child labor and the impact on health in adulthood in Brazil from 1998 to 2008. Cadernos de Saúde Pública, 31 (5), 1071-1083. https://doi.org/10.1590/0102-311X00009914

Nunes, M. \& Torrenté, M. (2009). Estigma e violências no trato com a loucura: narrativas de centros de atenção psicossocial, Bahia e Sergipe. Revista de Saúde Pública, 43(1), 101-108. https://doi.org/10.1590/S0034-89102009000800015

Oliveira, I. C., Nascimento, I., Coutinho, E. S. F., Pinto, V. A. M., Vilanova, A., Appolinario, J. C., \& Cavalcanti, M. T. (2018). Clinical stability, diagnosis and catchment area: the patients of a university-based psychiatric outpatient clinic. Jornal Brasileiro de Psiquiatria, 67 (4), 213-222. https://doi.org/10.1590/0047-2085000000208

Organização Internacional do Trabalho. (2018, 2 de maio). OIT: quase dois terços da força de trabalho global estão na economia informal [Notícias]. http://www.ilo.org/brasilia/noticias/WCMS_627643/lang--pt/index.htm

Organização Pan-Americana de Saúde. (2018, 27 de abril). Folha informativa-Transtornos mentais. Pan American Health Organization. https:/www.paho.org/bra/index.php?option=com_content\&view=article\&id=5652:folhainformativa-transtornos-mentais\&Itemid $=839$

Pereira, A. R. \& Joazeiro, G. (2015). Percepção da internação em hospital psiquiátrico por pacientes com diagnóstico de esquizofrenia. O Mundo da saúde, 39(4), 476-483. 
Histórias de vida e estigma de trabalhadores com transtornos mentais acompanhados em ambulatório especializado

Pinho, P. S. \& Araújo, T. M. (2012). Associação entre sobrecarga doméstica e transtornos mentais comuns em mulheres. Revista Brasileira de Epidemiologia, 15(3), 560-572. https://doi.org/10.1590/S1415-790X2012000300010

Praun, L. (2016). A solidão dos trabalhadores: sociabilidade contemporânea e degradação do trabalho. Cadernos de Psicologia Social do Trabalho, 19(2), 147-160. https://doi.org/10.11606/issn.1981-0490.v19i2p147-160

Previdência Social. (2017). Boletim quadrimestral sobre benefícios por incapacidade 2017. Previdência Social. http://www.previdencia.gov.br/saude-e-seguranca-do-trabalhador/boletim-quadrimestral/

Rocha, F. L., Hara, C. \& Paprocki, J. (2015). Doença mental e estigma. Revista Médica de Minas Gerais, 25(4), 590-596. http://www.rmmg.org/exportar-pdf/1876/v25n4a19.pdf

Sadock, B. Sadock, V. A., \& Ruiz, P. (Orgs). (2017). Compêndio de Psiquiatria: ciência do comportamento e psiquiatria clínica

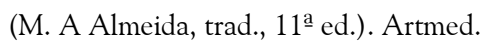

Salles, M. M. \& Barros, S. (2013). Representações sociais de usuários de um Centro de Atenção Psicossocial e pessoas de sua rede sobre doença mental e inclusão social. Saúde e Sociedade, 22 (4), 1059-1071. https://doi.org/10.1590/S010412902013000400009

Sato, L., Coutinho, M. C., \& Bernardo, M. H. (2017). A perspectiva da Psicologia Social do Trabalho. In M. C. Coutinho, M. H. Bernardo, \& L. Sato (Orgs.), Psicologia Social do Trabalho. Vozes.

Seligmann-Silva, E., Bernardo, M. H., Maeno, M., \& Kato, M. (2010). O mundo contemporâneo do trabalho e a saúde mental do trabalhador. Revista Brasileira de Saúde Ocupacional, 35(122), 187-191. https://doi.org/10.1590/S0303. 76572010000200002

Silva, M. L. O. (2002). Adultização da infância: o cotidiano das crianças trabalhadoras no mercado Ver-o-peso, em Belém do Pará. Serviço Social \&ु Sociedade, 23(69), 151-172.

Souza, E. L. C. \& Pontili, R. M. (2007). Trabalho infantil e sua influência sobre a renda e a escolaridade da população trabalhadora do Paraná-BR. http://www.economiaetecnologia.ufpr.br/XI_ANPEC-Sul/artigos_pdf/a2/ANPEC-Sul-A2-18trabalho_infantil_e_sua_.pdf

Spencer, H. (1851). Social statics. John Chapman.

Stiglitz, J. (2002). A globalização e seus malefícios. A promessa não cumprida de benefícios globais. Futura.

Thomé, L. D., Telmo, A. Q., \& Koller, S. H. (2010). Inserção laboral juvenil: contexto e opinião sobre definições de trabalho. Paidéia (Ribeirão Preto), 20(46), 175-185. https://doi.org/10.1590/S0103-863X2010000200005

Vechi, L. G., Chirosi, P. S., \& Prado, J. N. C. (2017). A inserção social pelo trabalho para pessoas com transtorno mental: uma análise de produção científica. Revista Psicologia e Saúde, 9(1), 111-123. https://doi.org/10.20435/pssa.v9i1.368

Vieira, C. E. C., Silva, C. A., Silva, K. F. A., Alves, M. A., \& Martins, M. O. (2016). Impactos picossociais do desemprego sobre a saúde mental e subjetividade de trabalhadores de Arcos/MG. Percurso Acadêmico, 6(11), 292-295. http://periodicos.pucminas.br/index.php/percursoacademico/article/view/9109

Zambroni-de-Souza, P. C. (2006a). Trabalho, organização e pessoas com transtornos mentais graves. Cadernos de Psicologia Social do Trabalho, 9(1), 91-105. https://doi.org/10.11606/issn.1981-0490.v9i1p91-105

Zambroni-de-Souza, P. C. (2006b). Trabalhando com saúde: trabalho e transtornos mentais graves. Psicologia em Estudo, 11(1), 175-183. https://doi.org/10.1590/S1413-73722006000100020

Zanello, V., Fiuza, G., \& Costa, H. S. (2015). Saúde mental e gênero: facetas gendradas do sofrimento psíquico. Fractal: Revista de Psicologia, 27(3), 238-246. https://doi.org/10.1590/1984-0292/1483

Endereço para correspondência alegeremiasas@gmail.com
Recebido em: 29/05/2020

Revisado em: 09/06/2021

Aprovado em: 14/06/2021

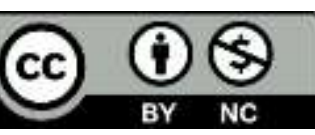

